\title{
RELAÇÕES DE BROMELIÁCEAS EPIFÍTICAS COM FATORES AMBIENTAIS EM PLANÍCIES DE INUNDAÇÃO DO RIO IGUAÇU, PARANÁ, BRASIL
}

\author{
Annete Bonnet ${ }^{1}$, Gustavo Ribas Curcio ${ }^{2}$, Osmir José Lavoranti ${ }^{3}$, Murilo Lacerda Barddal ${ }^{4}$, \\ Carlos Vellozo Roderjan ${ }^{5}$

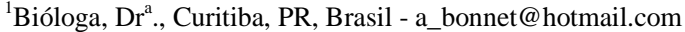 \\ ${ }^{2}$ Eng. Agrônomo, Dr., Embrapa Florestas, Colombo, PR, Brasil - curcio@cnpf.embrapa.br \\ ${ }^{3}$ Estatístico, Dr., Embrapa Florestas, Colombo, PR, Brasil - osmir@ cnpf.embrapa.br \\ ${ }^{4}$ Eng. Florestal, Dr., Copel, Curitiba, PR, Brasil - murilo.barddal@ copel.com \\ ${ }^{5}$ Eng. Florestal, Dr., Depto. de Ciências Florestais, UFPR, Curitiba, PR, Brasil - roderjan@ufpr.br \\ Recebido para publicação: 13/06/2008 - Aceito para publicação: 05/04/2008
}

\begin{abstract}
Resumo
Um total de 14 espécies de bromeliáceas epifíticas foi registrado na planície do rio Iguaçu, sendo algumas exclusivas da Floresta Ombrófila Densa, outras da Floresta Estacional Semidecidual e um terceiro grupo comum às duas unidades fitogeográficas. O número de espécies diminuiu para jusante do rio, em coerência à equivalente redução na disponibilidade hídrica definida pelos tipos climáticos. As superfícies geomórficas de degradação apresentaram os maiores índices de diversidade, em conformidade ao seu maior tempo de formação e presença de solos semi e não-hidromórficos. Em escala local, a largura máxima da planície e a largura média do rio estão negativamente correlacionadas com a riqueza de bromeliáceas, o que remete à existência de forte intervenção antrópica. A proximidade dos forófitos com o rio influencia positivamente a riqueza de bromeliáceas, provavelmente pelo aumento em umidade e luminosidade. Do mesmo modo, os forófitos com os maiores diâmetros de fuste apresentam maior riqueza de bromeliáceas, indicando, principalmente, que o tempo de exposição do substrato é importante, o que concorda com a literatura. A manutenção de florestas próximas aos cursos de água e grandes indivíduos arbóreos é fundamental para a preservação de bromeliáceas epifíticas nas planícies do rio Iguaçu.

Palavras-chave: Planície fluvial; clima; solos; umidade; diâmetros arbóreos.
\end{abstract}

\begin{abstract}
Relationships of epiphytic bromeliads with environmental factors at Iguaçu river floodplains, Parana, Brazil. A total of 14 epiphytic bromeliad species have been recorded at Iguaçu river floodplain, some being exclusive to the Ombrophilous Dense Forest, others to the Semideciduous Seasonal Forest, and one third group common to the two vegetation types. The species number decreased downstream along the river, in coherence to the equivalent reduction in the water availability defined by the climatic types. The degradation geomorphic surfaces presented the highest diversity indexes, which can be associated to the longest developing time of these geomorphic features and the presence of non-hydromorphic and semihydromorphic soils. In local scale, the maximum width of the floodplain and the average width of the river are negatively correlated with bromeliad richness, which is associated to strong anthropogenic disturbance. The proximity of the phorophytes with the river influenced positively bromeliad richness, probably, through the humidity and luminosity increment. At the same way, the phorophytes with the largest diameters presented greater richness of bromeliads, indicating, principally, that the time of exposition of substrate is important, what agrees with literature. The maintenance of forests close to streams and large trees is fundamental to epiphytic bromeliad conservation purposes at Iguaçu river floodplains. Keywords: River floodplain; climate; soils; humidity; arboreal diameters.
\end{abstract}

\section{INTRODUÇÃO}

Os epífitos, como componentes importantes da diversidade de florestas tropicais e subtropicais, também fazem parte das duas grandes unidades fitogeográficas dominantes no rio Iguaçu, a Floresta Ombrófila Mista e a Floresta Estacional Semidecidual, que se sucedem conforme o gradiente climático. 
No Brasil, os epífitos foram estudados, principalmente, no Sul e Sudeste, através de levantamentos em diversas unidades fitogeográficas. Em planícies fluviais, as bromeliáceas, mais especificamente, foram objeto de pesquisa de Fischer; Araújo (1995) no litoral do estado de São Paulo. Em outros estudos, essa família foi analisada em planícies fluviais apenas como parte de levantamentos florísticos e estudos ecológicos do grande grupo de plantas epifíticas (STEEGE; CORNELISSEN, 1989; SILVA et al., 1997; DITTRICH et al., 1999; MAMEDE et al., 2001; KERSTEN; SILVA, 2002; ROGALSKI; ZANIN, 2003; GIONGO; WAECHTER, 2004).

A bacia do rio Iguaçu, considerada a mais importante do Paraná devido ao seu papel no desenvolvimento do estado e extensão de áreas drenadas $\left(70.800 \mathrm{~km}^{2}\right)$, estende-se de leste para oeste pelos três planaltos paranaenses, em uma extensão de $910 \mathrm{~km}$ (MAACK, 2002), atravessando e modelando relevos, desde as suas nascentes, na Serra do Mar, até sua foz, no rio Paraná. Os planaltos paranaenses, que também se sucedem de leste para oeste do estado, são regiões de paisagens naturais, definidos por Maack (2002) com base na posição das escarpas, vales de rios e divisores de águas, além do caráter fisiográfico unitário dessas paisagens. O clima também se modifica de leste para oeste, predominando o tipo $\mathrm{Cfb}$ no primeiro e no segundo planalto e $\mathrm{Cfa}$ no terceiro planalto. $\mathrm{O}$ primeiro apresenta temperatura média do mês mais frio entre $-3^{\circ} \mathrm{C}$ e $18{ }^{\circ} \mathrm{C}$, e do mês mais quente abaixo de $22^{\circ} \mathrm{C}$, verões frescos, sem estação seca definida; o tipo Cfa difere por apresentar a temperatura média do mês mais quente acima de $22{ }^{\circ} \mathrm{C}$, verões quentes e geadas pouco frequentes. Nessa região, existe uma tendência de concentração das chuvas no verão, contudo sem estação seca definida (IAPAR, 1994).

A vegetação associada ao rio Iguaçu ocupa distintas feições geomorfológicas que formam as margens conforme o padrão de leito predominante, resultando em grande heterogeneidade fisionômica e florística das florestas. O padrão de leito meandrante livre, que o rio assume no primeiro e segundo planaltos paranaenses, condiciona a formação de amplas planícies de até $5 \mathrm{~km}$ de largura, com zonas de deposição e de retiradas de sedimentos das margens, assim como distintas classes de drenagem dos solos. As florestas, comumente com baixa riqueza florística, são descontínuas devido às zonas de solos hidromórficos que condicionam a inserção de áreas com plantas herbáceas (CURCIO, 2006). Segundo esse autor, no terceiro planalto, o rio apresenta padrão de leito encaixado, determinado por lineamentos geológicos formados em rochas efusivas. Esse padrão gera planícies estreitas, com pouca variação geomorfológica e pedológica, além de florestas com maior número de espécies de árvores, que se estendem de modo contínuo nas margens soerguidas, formadas por solos livres de hidromorfia.

Considerando a grande diversidade ambiental existente, em diferentes escalas, ao longo do rio Iguaçu, é provável que os padrões de ocorrência das bromeliáceas sejam diferentes de montante para jusante do rio, pois essas plantas respondem fortemente às condições macro e microclimáticas, assim como ao estado de degradação da floresta e às características do substrato (GENTRY; DODSON, 1987; STEEGE; CORNELISSEN, 1989; BONNET; QUEIROZ, 2006). A umidade e a temperatura são os dois principais parâmetros físicos que comandam a distribuição das bromeliáceas epifíticas em grandes paisagens e nos ambientes que as compõem. Regiões mais secas e estações com baixa precipitação bem definidas geram uma diminuição da diversidade dessas plantas (WAECHTER, 1992; DISLICH; MANTOVANI, 1998; ZOTZ; HIETZ, 2001). Baixas temperaturas também podem limitar seu crescimento e sobrevivência, mas são ainda mais graves quando acompanhadas simultaneamente de estresse provocado pela seca (ZOTZ; HIETZ, 2001). Por outro lado, ambientes mais conservados e grandes indivíduos arbóreos apresentam maior diversidade de bromeliáceas (MARTIN et al., 2004; WOLF, 2005; FLORES-PALACIOS; GARCÍA-FRANCO, 2006; BONNET, et al., 2007). Quando considerada a diversidade de forófitos em uma mesma formação florestal, vários fatores influenciam na ocorrência e distribuição das epífitas, como velocidade de crescimento, qualidade, posição e estabilidade do substrato, além de acúmulo de matéria orgânica (BENZING, 1990; HIETZ; HIETZ-SEIFERT, 1995; HIETZ, 1997; BADER et al., 2000).

Este estudo objetiva, com base em levantamentos sistemáticos realizados em 24 áreas de estudo instaladas nas planícies do rio Iguaçu, investigar as relações entre o número de espécies de bromeliáceas epifíticas registrado nos forófitos e variáveis ambientais analisadas em diferentes escalas da paisagem. Considerando que bromeliáceas são influenciadas, simultaneamente, por uma série de variáveis, empregou-se a análise multivariada para analisar, nas planícies em questão, quais fatores são mais importantes na definição da riqueza dessas plantas, dentre os climáticos, geomorfológicos, pedológicos ou estruturais da floresta. 


\section{MATERIAL E MÉTODOS}

\section{Área de estudo}

O estudo foi realizado em áreas distribuídas nas planícies do rio Iguaçu, estado do Paraná, Brasil, entre as coordenadas geográficas $25^{\circ} 34^{\prime}-26^{\circ} 17^{\prime} \mathrm{S}$ e $49^{\circ} 59^{\prime}-50^{\circ} 53^{\prime} \mathrm{W}$. Para análise das variáveis ambientais, o rio foi segmentado em 12 compartimentos geológicos (CURCIO, 2006), com o seguinte ordenamento de montante para jusante: Complexo Gnáissico Migmático Costeiro, no Primeiro Planalto; Campo do Tenente, Furnas, Mafra/Rio do Sul, Rio Bonito, Palermo, Irati, Serra Alta, Teresina e Rio do Rasto no Segundo Planalto (Figura 1). No Terceiro Planalto, na área do Parque Nacional do Iguaçu, foram estabelecidos os compartimentos Serra Geral I e Serra Geral II. O baixo número de compartimentos no Primeiro Planalto deve-se à grande extensão de áreas, próximas a Curitiba, com leito retificado e, no Terceiro Planalto, deve-se à inexistência de vegetação fluvial, suprimida por cinco grandes reservatórios hidrelétricos. No entanto, consideram-se representativas as florestas estudadas, em função dos curtos trechos de rio com vegetação ainda original nos dois planaltos e do alto nível de conservação das florestas inseridas no Parque Nacional do Iguaçu.

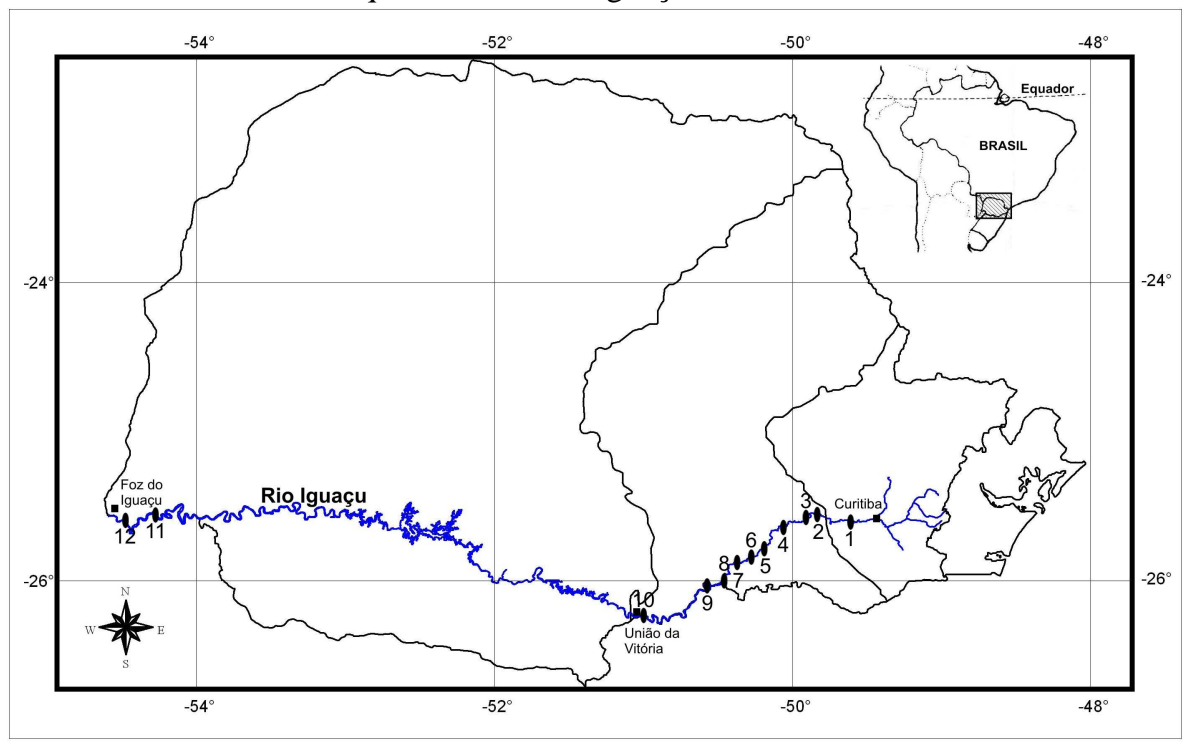

Figura 1. Localização dos compartimentos estabelecidos nas planícies do rio Iguaçu, PR. 1: GM Costeiro; 2: Campo do Tenente; 3: Furnas; 4: Mafra/Rio Sul; 5: Rio Bonito; 6: Palermo; 7 : Irati; 8: Serra Alta; 9: Teresina; 10: Rio do Rasto; 11: Serra Geral I; 12: Serra Geral II.

Figure 1. Localization of the compartments established at the Iguaçu river floodplains, PR. 1: GM Costeiro; 2: Campo do Tenente; 3: Furnas; 4: Mafra/Rio Sul; 5: Rio Bonito; 6: Palermo; 7: Irati; 8: Serra Alta; 9: Teresina; 10: Rio do Rasto; 11: Serra Geral I; 12: Serra Geral II.

Em cada um dos 12 compartimentos geológicos, foram selecionadas duas superfícies da planície fluvial, sendo uma de agradação, ou segmento convexo da curva, onde os sedimentos são depositados, e outra de degradação, ou lado côncavo da curva, de onde os sedimentos são erodidos pelo rio. Essa seleção deve-se à grande diferenciação existente entre as superfícies no aspecto geomorfológico e pedológico quando o rio assume padrão de leito meandrante livre.

De montante para jusante do rio, uma série de fatores ambientais se modificam, imprimindo características singulares a cada uma das 24 áreas de estudo (Tabela 1). Com a diminuição em altitude de leste para oeste do estado, modificam-se as variáveis climáticas e as larguras da planície e do rio, em função do padrão de leito e da presença de afluentes, assim como a altura de soerguimento das margens nas áreas de estudo e a saturação hídrica dos solos. A vegetação, do mesmo modo, apresenta distinta estrutura conforme as áreas de estudo, mas se relaciona, principalmente, com as unidades fitogeográficas dominantes. Nas planícies do Primeiro e Segundo planaltos predomina a Floresta Ombrófila Mista Aluvial montana (FOM), onde as comunidades arbóreas são dominadas por Sebastiania commersoniana 
(Baill.) L.B. Sm. e R.J. Downs (BARDDAL et al., 2004). Nas áreas do Terceiro Planalto, onde predomina a Floresta Estacional Semidecidual (FES), a vegetação está conservada apenas no Parque Nacional do Iguaçu, apresentando maior diversidade do componente arbóreo em relação à FOM (CURCIO, 2006).

Tabela 1. Variáveis climáticas e geomorfológicas das áreas de estudo na planície do rio Iguaçu, PR. Cmin = valores mínimos de dias de chuva/ano; Umin = valores mínimos de umidade relativa média mensal; Pmin = valores mínimos de precipitação média mensal; alti = altitude; $\mathrm{Lpla}=$ largura máxima da planície; Lrio = largura média do rio; Sorg = altura de soerguimento da margem; Aflu = presença de afluente $(\bullet)$.

Table 1. Climatic and geomorphologic variables of study areas at the Iguaçu river floodplains, PR. Cmin $=$ minimum days of rain/year; Umin $=$ minimum average humidity/month; Pmin $=$ minimum average precipitation $/$ month; alti $=$ altitude; Lpla $=$ maximum width of the floodplain; Lrio = medium width of the river; Sorg = height of river bank; Aflu = presence of tributary $(\bullet)$.

\begin{tabular}{|c|c|c|c|c|c|c|c|c|c|}
\hline Compartimento & Superfície & $\begin{array}{l}\text { Cmin } \\
\text { (dias) }\end{array}$ & $\begin{array}{c}\text { Umin } \\
(\%)\end{array}$ & $\begin{array}{l}\text { Pmin } \\
(\mathrm{mm})\end{array}$ & $\begin{array}{l}\text { alti } \\
(\mathrm{m})\end{array}$ & $\begin{array}{c}\text { Lpla } \\
\text { (m) }\end{array}$ & $\begin{array}{c}\text { Lrio } \\
\text { (m) }\end{array}$ & $\begin{array}{c}\text { Sorg } \\
\text { (m) }\end{array}$ & Aflu \\
\hline \multirow{2}{*}{ GM Costeiro } & agradação & 137 & 69,7 & 8,8 & 878 & 900 & 35 & 1,0 & \\
\hline & degradação & 137 & 69,7 & 8,8 & 878 & 900 & 35 & 1,7 & \\
\hline \multirow{2}{*}{ Campo do Tenente } & agradação & 137 & 69,7 & 8,8 & 865 & 100 & 45 & 2,1 & \\
\hline & degradação & 137 & 69,7 & 8,8 & 865 & 100 & 45 & 4,0 & \\
\hline \multirow{2}{*}{ Furnas } & agradação & 137 & 69,7 & 8,8 & 832 & 350 & 17,5 & 1,0 & \\
\hline & degradação & 137 & 69,7 & 8,8 & 832 & 350 & 17,5 & 1,0 & $\bullet$ \\
\hline \multirow{2}{*}{ Mafra/Rio do Sul } & agradação & 137 & 69,7 & 8,8 & 788 & 400 & 45 & 3,5 & \\
\hline & degradação & 137 & 69,7 & 8,8 & 788 & 400 & 45 & 4,0 & \\
\hline \multirow{2}{*}{ Rio Bonito } & agradação & 137 & 69,7 & 8,8 & 769 & 2.375 & 50 & 1,8 & \\
\hline & degradação & 120 & 71,1 & 4,0 & 769 & 2.375 & 50 & 2,3 & $\bullet$ \\
\hline \multirow{2}{*}{ Palermo } & agradação & 120 & 71,1 & 4,0 & 764 & 2.125 & 55 & 1,0 & \\
\hline & degradação & 120 & 71,1 & 4,0 & 764 & 2.125 & 55 & 3,0 & \\
\hline \multirow{2}{*}{ Irati } & agradação & 120 & 71,1 & 4,0 & 761 & 3.500 & 60 & 1,5 & \\
\hline & degradação & 120 & 71,1 & 4,0 & 761 & 3.500 & 60 & 3,5 & \\
\hline \multirow{2}{*}{ Serra Alta } & agradação & 120 & 71,1 & 4,0 & 758 & 5.125 & 62 & 1,6 & \\
\hline & degradação & 120 & 71,1 & 4,0 & 758 & 5.125 & 62 & 3,0 & \\
\hline \multirow{2}{*}{ Teresina } & agradação & 120 & 71,1 & 4,0 & 756 & 1.750 & 130 & 1,8 & $\bullet$ \\
\hline & degradação & 120 & 71,1 & 4,0 & 756 & 1.750 & 130 & 3,0 & $\bullet$ \\
\hline \multirow{2}{*}{ Rio do Rasto } & agradação & 120 & 71,1 & 4,0 & 753 & 5.000 & 250 & 7,0 & $\bullet$ \\
\hline & degradação & 120 & 71,1 & 4,0 & 753 & 5.000 & 250 & 4,5 & $\bullet$ \\
\hline \multirow{2}{*}{ Serra Geral I } & agradação & 99 & 62,1 & 2,5 & 233 & 875 & 600 & 4,5 & \\
\hline & degradação & 99 & 62,1 & 2,5 & 233 & 875 & 600 & 6,0 & \\
\hline \multirow{2}{*}{ Serra Geral II } & agradação & 99 & 62,1 & 2,5 & 219 & 950 & 600 & 5,5 & \\
\hline & degradação ${ }^{1}$ & 99 & 62,1 & 2,5 & 219 & 950 & 600 & 6,0 & \\
\hline
\end{tabular}

\section{Procedimento amostral}

Os fatores ambientais foram analisados em diferentes escalas da paisagem e se referem a dados climáticos, geomorfológicos, pedológicos e espaciais, além de características da floresta e dos indivíduos arbóreos. Na escala dos compartimentos geológicos (Figura 1), foram registrados os dados climáticos e a altitude (Tabela 1). As variáveis climáticas foram obtidas a partir dos dados coletados nas estações de Curitiba, União da Vitória e Foz do Iguaçu, gentilmente cedidas pelo Instituto Tecnológico Simepar (PR), e representadas pelos valores mínimos de dias de chuva/ano (Cmin), de umidade relativa média mensal (Umin) e de precipitação média mensal (Pmin). As altitudes (alti) foram registradas com GPS (Garmin 76CSx) e corrigidas com base nas cartas planialtimétricas da região, na escala 1:50.000 (IBGE).

Nas áreas de estudo, foram registradas características geomorfológicas, como a largura máxima da planície (Lpla) e a largura média do rio (Lrio), além da presença de afluentes (aflu), utilizando-se fotografias aéreas, escala 1:25.000, ano de 1980 (Tabela 1). Foram anotadas, em campo, as alturas de 
soerguimento das margens (sorg), com base em uma série de observações fluviométricas ao longo dos trabalhos. O regime hídrico dos solos predominantes nas áreas foi classificado conforme Embrapa (1999), baseando-se em dados de permeabilidade saturada e características morfológicas (CURCIO, 2006). As classes de drenagem dos solos foram expressas pelas categorias não-hidromórfico (nh), semihidromórfico (sh) e hidromórfico (h).

Em cada área de estudo, foram instaladas nove parcelas com $5 \times 10 \mathrm{~m}$, para registro das bromeliáceas nos forófitos. As parcelas foram ordenadas em três faixas paralelas ao rio e contíguas, a partir da sua margem. A distribuição das faixas tem o objetivo de refletir a disposição espacial das bromeliáceas em relação ao canal e foram analisadas, espacialmente, se eram adjacentes ao rio (rio), a solos hidromórficos (hidro) ou distante das duas feições (dst). Todas as árvores incluídas nas parcelas foram avaliadas quanto à presença de espécies de bromeliáceas. O critério de inclusão dos indivíduos arbóreos nas parcelas foi apresentar perímetro à altura do peito (PAP) igual ou superior a $15 \mathrm{~cm}$. Com os dados coletados nas faixas de parcelas, foram calculados os índices de Shannon (Hi) e Pielou (E), densidade absoluta (DA), dominância absoluta (DoA) e riqueza de árvores (Sarv) (CURCIO, 2006). Foram feitas observações sobre 2.813 forófitos, registrando-se o número de espécies de bromeliáceas existente sobre cada árvore (BONNET, 2006), além da espécie, diâmetro (DAP), altura total (H), número de perfilhos (perf), altura de início da copa (PIM), grau de inclinação do fuste em relação ao solo (incl) e presença de plântulas (plant) (CURCIO, 2006).

Nas áreas de estudo, além da amostragem quantitativa, foi realizado levantamento florístico de bromeliáceas. Percorrendo-se aproximadamente 1 ha ao redor da área das parcelas, foram registradas todas as espécies, sempre respeitando os limites da planície fluvial. Exemplares férteis de Bromeliaceae foram depositados no Herbário da Universidade Federal do Paraná (EFC). Para identificação das plantas arbóreas e epifíticas em campo, quando necessário, utilizou-se binóculo e técnicas de escalada em árvores, seguidos por consultas a especialistas, em alguns casos. Os nomes científicos foram verificados em IPNI (2007).

\section{Análise dos dados}

Os dados de presença das bromeliáceas sobre os forófitos foram utilizados para o cálculo do valor de importância epifítico (VIE) de cada espécie de bromélia, computado a partir da média das frequências relativas sobre espécies forofíticas (Sri) e indivíduos forofíticos (Nri) em cada área de estudo (WAECHTER, 1992). As frequências relativas sobre indivíduos forofíticos também foram empregadas no cálculo dos índices de diversidade de Shannon e equabilidade de Pielou, cujas variâncias e comparações foram analisadas através do método Jackknife (EFRON, 1979). Foi calculada a diversidade intercomunitária ou beta (Bt), de Wilson; Shmida (MAGURRAN, 1988), que estima o grau de substituição específica entre as áreas de estudo. As distâncias de Jaccard, calculadas entre os compartimentos, foram utilizadas para confeccionar o algoritmo de agrupamentos, elaborado com base na metodologia hierárquica-aglomerativa das médias das distâncias.

Para verificar o efeito das variáveis ambientais, referentes a dados climáticos, geomorfológicos, pedológicos e espaciais, além de características da floresta e dos indivíduos arbóreos, sobre a riqueza de bromeliáceas, foi empregada, inicialmente, a análise de componentes principais. Esta análise selecionou, dentre as 29 variáveis ambientais levantadas, aquelas que mais explicavam a variabilidade total do conjunto de dados. Na sequência, foi utilizada a análise de regressão múltipla (DRAPER; SMITH, 1981) para verificar quais componentes apresentavam relação significativa com a riqueza de bromeliáceas. As variáveis ambientais foram padronizadas conforme a fórmula conhecida como ajuste de extensão (range extension), em que $\mathrm{Y}=\mathrm{X}-\mathrm{X}_{\min } /\left(\mathrm{X}_{\max }-\mathrm{X}_{\min }\right)$. Foi utilizado o Sistema $\mathrm{SAS}{ }^{\circledR}$ para analisar os dados e processar a análise de componentes principais e a análise de regressão múltipla.

\section{RESULTADOS}

Foram registradas, na planície do rio Iguaçu, 14 espécies epifíticas de Bromeliaceae, pertencentes a seis gêneros distintos (Tabela 2). Entre as áreas de estudo, o número de espécies foi variável, tendo sido registrada a menor riqueza em Serra Geral II agradação (duas), e a maior em duas áreas, Furnas agradação e Rio Bonito degradação (nove). 
Os índices de Shannon e Pielou foram extremamente baixos e variáveis entre os compartimentos e entre as superfícies (Tabela 2). Os maiores valores concentraram-se no trecho compreendido entre o segundo e o sexto compartimento, respectivamente, Campo do Tenente e Palermo. Levando-se em conta a superfície geomórfica, as degradações apresentaram, de modo geral, os índices de Shannon e de Pielou mais altos. Por outro lado, há uma clara diminuição na riqueza e na diversidade nas áreas da FES, o que se refletiu no índice de diversidade beta (Bt) (ou diversidade intercomunitária), cujo cálculo resultou no valor de 1,12 .

Tabela 2. Valor de importância epifítico (VIE) das bromeliáceas e Índices de Shannon (H') e de Pielou (E) das áreas de estudo estabelecidas nas planícies do rio Iguaçu, com indicação das espécies registradas apenas no levantamento florístico $(\bullet)$. Acrônimos formados pelas letras iniciais das áreas de estudo, seguidas por a = superfície de agradação ou por $\mathrm{d}=$ superfície de degradação. Em cada coluna, letras minúsculas distintas indicam índices significativamente diferentes $(\mathrm{p}<0,05)$, conforme o teste Jackknife.

Table 2. Importance value of bromeliad species (VIE) and Shanon (H') and Pielou (E) indexes of study areas of Iguaçu river floodplains, with indication of the species only registered on floristic survey $(\bullet)$. Acronyms formed by first letters of study areas names, followed by a $=$ aggradation surface or by $\mathrm{d}=$ degradation surface. In each column, distinct small letters indicate significantly different indexes $(\mathrm{p}<0.05)$, according to Jackknife test.

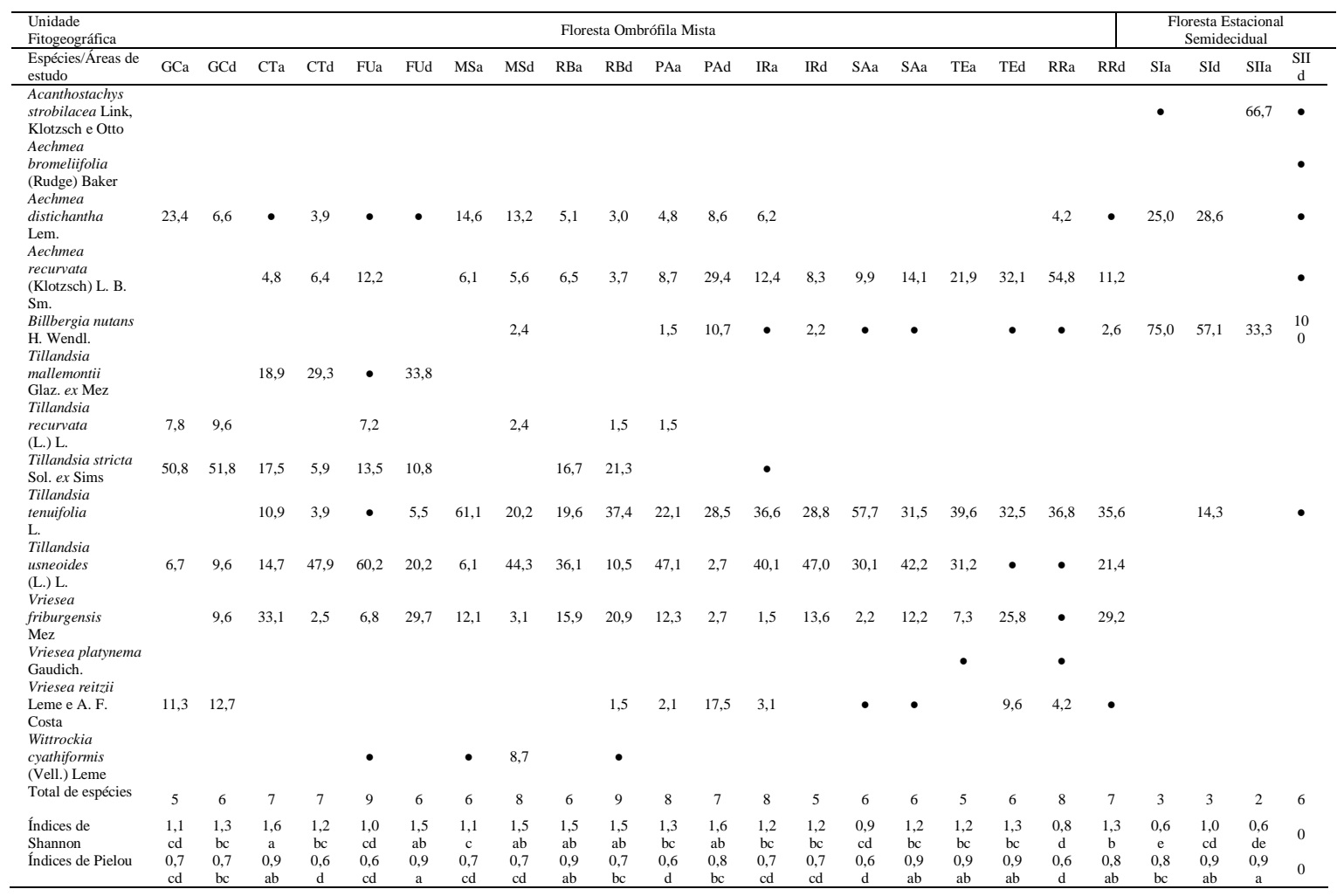

Duas espécies foram exclusivas da Floresta Estacional Semidecidual (FES) - Acanthostachys strobilacea e Aechmea bromeliifolia -, enquanto oito foram restritas à Floresta Ombrófila Mista (FOM) Tillandsia mallemontii, T. stricta, T. recurvata, T. usneoides, Vriesea friburgensis, V. platynema, V. reitzii e Wittrockia cyathiformis. Quatro espécies foram comuns às duas unidades fitogeográficas: Aechmea distichantha, A. recurvata, Billbergia nutans e Tillandsia tenuifolia, todavia nenhuma ocorreu em todas as áreas de estudo. 
Tillandsia tenuifolia e T. usneoides foram as espécies mais frequentes na maioria das áreas onde predomina a FOM, enquanto Billbergia nutans se destaca nas áreas onde predomina a FES (Tabela 2). Aechmea bromeliifolia e Vriesea platynema foram registradas apenas no levantamento florístico e em poucas áreas de estudo: Serra Geral II degradação (A. bromeliifolia), Teresina agradação e Rio do Rasto agradação ( $V$. platynema).

A análise dos agrupamentos gerados com base no índice de Jaccard revela a existência de dois grandes grupos (Figura 2), sendo um deles formado pelos compartimentos inseridos na FOM e outro por aqueles inseridos na FES. Considerando a FOM, os compartimentos com maior similaridade são Teresina e Serra Alta, seguidos pelos compartimentos Rio Bonito e Furnas.

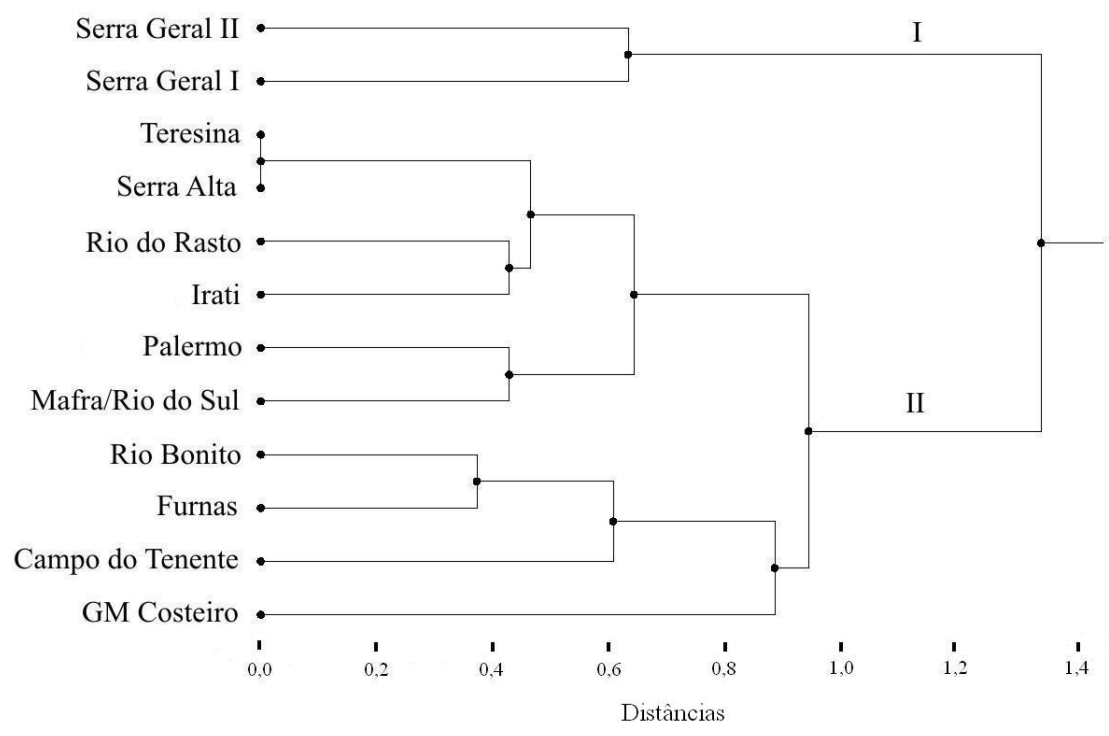

Figura 2. Dendrograma dos compartimentos da planície do rio Iguaçu, baseado na similaridade das bromeliáceas epifíticas. I: Floresta Estacional Semidecidual; II: Floresta Ombrófila Mista.

Figure 2. I: Dendrogram reporting relationships among compartments of Iguaçu river floodplain, based on the similarity of epiphytic bromeliads. I: Seasonal Semideciduous Forest; II: Mixed Ombrophilous Forest.

Nas áreas de estudo inseridas no Primeiro e Segundo planaltos, onde predomina a FOM, os maiores forófitos amostrados pertencem às espécies Araucaria angustifolia (Bertol.) O. Kuntze, Erythrina crista-galli L., Luehea divaricata Mart., Matayba elaeagnoides Radlk. e Vitex megapotamica (Spreng.) Mold. Sob predomínio da FES, os maiores indivíduos arbóreos nas áreas do Terceiro Planalto foram Parapiptadenia rigida (Benth.) Brenan, Diatenopteryx sorbifolia Radlk., Chrysophyllum gonocarpum (Mart. e Eichler ex Miq.) Engl., Nectandra megapotamica Mez, Erythrina falcata Benth., Patagonula americana L. e Peltophorum dubium (Spreng.) Taub.

Através de processos interativos de análise de componentes principais, foram selecionadas 16 componentes (Tabela 3), com base nos critérios das comunalidades superiores a 0,7 e autovalores superiores a 1, segundo Kaiser (1958). Na sequência, a análise de regressão múltipla revelou seis variáveis ambientais que apresentaram relação significativa (p-valor < 0,0001) com o número de espécies de bromélias (Tabela 4).

Segundo a análise multivariada, as riquezas de bromeliáceas registradas sobre cada um dos 2.813 forófitos analisados responderam, na planície do rio Iguaçu, a fatores geomorfológicos e estruturais da floresta. Os resultados mostram que a largura máxima da planície e a largura média do rio estão negativamente relacionadas com o número de espécies, ou seja, quanto mais largos a planície e o rio Iguaçu, menor a riqueza de bromeliáceas (Tabela 4). Por outro lado, a proximidade dos indivíduos arbóreos com o rio está positivamente relacionada com o número de espécies, assim como a presença de

FLORESTA, Curitiba, PR, v. 40, n. 1, p. 193-208, jan./mar. 2010. 
solos não e semi-hidromórficos. Considerando a comunidade arbórea, quanto maior o diâmetro dos indivíduos arbóreos, maior a riqueza específica de bromeliáceas na planície do rio Iguaçu.

As variáveis que representavam os valores mínimos de precipitação média mensal e parcelas localizadas distantes do rio e dos solos hidromórficos revelaram-se combinações lineares de outras variáveis e, consequentemente, foram excluídas na análise de regressão.

Tabela 3. Comunalidades e cargas fatoriais das variáveis, porcentagem de explicação dos fatores resultantes da análise de componentes principais. Umin: menor umidade média/mês; Cmin: valor mínimo dias chuva/ano; Sh: faixa de parcelas em solos semi-hidromórficos; Nh: faixa de parcelas em solos não-hidromórficos; Lpla: largura máxima da planície; Pmin: valor mínimo de precipitação média mensal; Rio: faixa de parcelas adjacente ao rio; Dst: faixa de parcelas distante do rio e de solos hidromórficos; DAP: diâmetro à altura do peito; H: altura total das árvores; Hidro: faixa de parcelas adjacente a solos hidromórficos; VA: variância acumulada.

Table 3. Comunalities and scoring coefficients of the variables, explanation percentage of the resulting factors of principal component analysis. Umin: minimum average humidity/month; Cmin: minimum days of rain/year; Sh: strips of plots at semihydromorphic soils; Nh: strips of plots at no hydromorphic soils; Lpla: maximum width of the floodplain; Pmin: minimum average precipitation/month; Rio: strip of plots is adjacent to the river; Dst: strips of plots far from the river and from hydromorphic soils; DAP: breast height diameter; $\mathrm{H}$ : total height from the trees; Hidro: strips of plots adjacent to the hydromorphic soils; VA: accumulated variance.

\begin{tabular}{lcccccccc}
\hline Variáveis & Comunalidade & Fator1 & Fator2 & Fator3 & Fator4 & Fator5 & Fator6 & Fator7 \\
\hline Altitude & 0,9925 & 0,9572 & $-0,2190$ & 0,1384 & 0,0060 & 0,0244 & $-0,0322$ & 0,0857 \\
Umin & 0,9698 & 0,8761 & $-0,1590$ & 0,1131 & 0,3920 & 0,0061 & $-0,0411$ & 0,0929 \\
Cmin & 0,9800 & 0,8754 & $-0,1859$ & 0,0655 & $-0,4145$ & 0,0308 & $-0,0163$ & 0,0419 \\
Largura média rio & 0,9532 & $-0,9409$ & 0,1694 & $-0,1693$ & 0,0290 & $-0,0097$ & $-0,0113$ & $-0,0968$ \\
Índice Shannon & 0,9784 & $-0,2617$ & 0,9267 & $-0,1595$ & 0,1144 & $-0,1083$ & 0,0069 & $-0,0276$ \\
N $^{\circ}$ espécies árvores & 0,8270 & $-0,1657$ & 0,8548 & $-0,0638$ & $-0,0586$ & 0,2358 & $-0,0046$ & 0,0753 \\
Índice Pielou & 0,8758 & $-0,2018$ & 0,8403 & $-0,1151$ & 0,1832 & $-0,2815$ & $-0,0022$ & $-0,0535$ \\
Sh & 0,9779 & 0,1480 & $-0,1285$ & 0,9634 & $-0,0066$ & 0,0227 & 0,0004 & 0,1034 \\
Nh & 0,9758 & $-0,1701$ & 0,1417 & $-0,9525$ & 0,0471 & $-0,04$ & 0,0076 & $-0,1251$ \\
Lpla & 0,9122 & 0,0739 & 0,0941 & $-0,0384$ & 0,9454 & 0,0142 & $-0,0203$ & 0,0431 \\
Pmin & 0,9434 & 0,6604 & $-0,1531$ & 0,0270 & $-0,6941$ & 0,0349 & $-0,0006$ & 0,0075 \\
Rio & 0,9848 & $-0,0398$ & $-0,0558$ & $-0,0429$ & $-0,0142$ & 0,8875 & $-0,0616$ & $-0,4320$ \\
Dst & 0,9808 & $-0,1186$ & 0,0451 & $-0,1428$ & $-0,0246$ & $-0,832$ & 0,0538 & $-0,4985$ \\
DAP & 0,7917 & $-0,0986$ & $-0,0257$ & $-0,0153$ & 0,1250 & 0,0758 & 0,8707 & $-0,0386$ \\
H & 0,7726 & 0,0595 & 0,0258 & 0,0095 & $-0,1532$ & $-0,1609$ & 0,8467 & 0,0449 \\
Hidro & 0,9976 & 0,1644 & 0,0106 & 0,1928 & 0,0402 & $-0,0494$ & 0,0074 & 0,9639 \\
Variância & - & 5,4677 & 2,0223 & 1,8681 & 1,6936 & 1,5165 & 1,3424 & 1,0033 \\
VA (\%) & - & 0,3417 & 0,4681 & 0,5849 & 0,6907 & 0,7855 & 0,8694 & 0,9321 \\
\hline
\end{tabular}

\section{DISCUSSÃO}

Quando comparados os dados de levantamentos conduzidos em planícies fluviais de distintos rios brasileiros (Tabela 5), grande parte da região Sul, pode-se afirmar que as riquezas de bromeliáceas são bastante semelhantes, apesar das diferentes metodologias empregadas. A semelhança é mantida quando consideramos estudos em outras formas de relevo no país (PETEAN, 2002; BORGO; SILVA, 2003; GAIOTTO; ACRA, 2005; BONNET et al., 2007) ou diminui em comparação a levantamentos feitos em áreas protegidas na Floresta Ombrófila Densa, onde foram registradas as maiores riquezas em bromeliáceas no Brasil (FONTOURA et al., 1997; SCHÜTZ-GATTI, 2000; MAMEDE et al., 2004; BREIER, 2005). Esses dados indicam que planícies fluviais, como feição geomórfica da paisagem, não podem ser relacionadas diretamente à menor riqueza em bromeliáceas. No entanto, a composição florística e a estrutura diferem entre comunidades epifíticas de planícies e de encostas, como registrado por Kersten (2006) para a Floresta Ombrófila Mista no Paraná. 
Tabela 4. Nível de significância, estimativa e erros dos parâmetros do modelo de regressão obtidos por componentes principais para o efeito do número de espécies de bromeliáceas. Coeficiente de determinação (R2): 0,8898; erro quadrático médio (EQM): 0,0117; número de observações (n): 2813.

Table 4. Significance level, parameter estimate and standard error of the regression model obtained by principal components to the effect of the number of bromeliad species. Determination coefficient (R2): 0,8898; average quadratic error; number of observations (n): 2813.

\begin{tabular}{lccc}
\hline Componentes principais & Prob $>\mathbf{t}$ & Estimativa & Erro \\
\hline Valor mínimo dias chuva/ano por estação meteorológica & 0,2372 & - & - \\
Menor umidade média/mês por estaçáo meteorológica & 0,2411 & - & - \\
Altitude na área de estudo & 0,0482 & - & - \\
Largura máxima da planície na região da área de estudo & $<0,0001$ & $-0,0830$ & 0,0064 \\
Largura média do rio na região da área de estudo & $<0,0001$ & $-0,1003$ & 0,0068 \\
Faixa de parcelas em solos semi-hidromórficos & $<0,0001$ & 0,0478 & 0,0046 \\
Faixa de parcelas em solos não-hidromórficos & $<0,0001$ & 0,0592 & 0,0045 \\
Faixa de parcelas adjacente ao rio & $<0,0001$ & 0,0522 & 0,0043 \\
Faixa de parcelas adjacente a solos hidromórficos & 0,521 & - & - \\
Diâmetro à altura do peito de cada árvore & $<0,0001$ & 0,4868 & 0,0338 \\
Altura total de cada árvore & 0,505 & - & - \\
Índice de Shannon das árvores por faixa de parcelas & 0,8929 & - & - \\
Índice de Pielou das árvores por faixa de parcelas & 0,0309 & - & - \\
Número de espécies de árvores por faixa de parcelas & 0,1371 & - & - \\
\hline
\end{tabular}

Tillandsia tenuifolia, apesar de ser uma das espécies com maior valor de importância nas florestas estudadas sob domínio da FOM, foi registrada nas duas unidades fitogeográficas estudadas (Tabela 2). O mesmo ocorreu com Billbergia nutans, com grande destaque na FES, mas comum nas florestas sob domínio da FOM. É provável que essas duas espécies, além de Aechmea distichantha e de A. recurvata, apesar de não terem sido registradas em todas as áreas estudadas, tenham existido originalmente em toda a extensão da planície do rio Iguaçu.

Os altos valores de importância de Tillandsia usneoides em grande parte das áreas sob domínio da FOM, onde ocorreu com exclusividade (Tabela 2), são, provavelmente, relacionados com as amplas planícies e grande distribuição de solos hidromórficos e semi-hidromórficos que ladeiam esse trecho do rio. A elevada saturação hídrica dos solos em locais de afloramento do lençol freático, como as bacias de inundação, associada à maior intensidade lumínica incidente nessas áreas com pouquíssimos indivíduos arbóreos (CURCIO, 2006) favorecem o crescimento de grandes agrupamentos dessa bromeliácea sobre os forófitos da floresta aluvial. Considerada heliófila e seletiva higrófita (REITZ, 1983), T. usneoides cresce em grandes agrupamentos nas árvores que margeiam o curso d'água e margeiam as zonas de maior hidromorfia dos solos, além dos indivíduos arbóreos que se destacam em altura na floresta.

Os dados indicam que as duas espécies com ocorrência exclusiva na FES, Acanthostachys strobilacea e Aechmea bromeliifolia, apresentam distribuição geográfica relacionada com essa unidade fitogeográfica, pois foram registradas sob seu domínio na região norte, centro-oeste e oeste do Paraná (BORGO et al., 2002; CERVI; BORGO, 2007; DETTKE et al., 2008) e norte e leste de São Paulo (PINTO et al., 1995; DISLICH; MANTOVANI, 1998).

A variabilidade de espécies encontrada nas planícies do rio Iguaçu deve-se às mudanças existentes nos atributos bióticos e abióticos das áreas de estudo. A diminuição na riqueza de bromeliáceas nas áreas sob domínio da FES, evidenciada através das riquezas e dos índices de Shannon (Tabela 2), corresponde ao gradiente leste-oeste de diminuição de espécies de bromeliáceas, já registrado em Santa Catarina por Reitz (1983). Do mesmo modo, o valor obtido no cálculo do índice de diversidade beta $(1,12)$ indica que houve uma clara substituição de espécies de montante para jusante do rio Iguaçu, equivalente à de 1,06 registrada ao longo de toda a planície costeira do Rio Grande do Sul (WAECHTER, 1992).

No Paraná, o baixo número de espécies na FES registrado pelo presente estudo é ratificado por levantamentos pontuais, como Bolós et al. (1992), Borgo et al. (2002), Cervi; Borgo (2007) e Dettke et 
al. (2008). Apesar da pouca importância das variáveis climáticas evidenciada pelas análises estatísticas no presente estudo (Tabela 4), a disponibilidade hídrica é um dos fatores mais importantes para a flora epifítica (GENTRY; DODSON, 1987; WAECHTER, 1992; DISLICH; MANTOVANI, 1998; ZOTZ; HIETZ, 2001). A umidade relativa do ar é menor na região da FES, apesar da maior precipitação média anual (Tabela 5), enquadrando-se na zona com $70-75 \%$ de umidade, enquanto as áreas estudadas da FOM apresentam umidade entre 80-85\% (IAPAR, 1994). Na região inserida na FOM, também existe maior uniformidade da distribuição da precipitação ao longo do ano, evidenciado através de um maior número de dias de chuva por ano, além de maiores valores mínimos de umidade relativa média mensal e de precipitação média mensal (Tabela 1). Para essa mesma região, Maack (2002) cita as zonas de neblina, formada nos meses de inverno, que, além de uma proteção da vegetação às geadas, também representa mais uma fonte de água para a vegetação epifítica.

Tabela 5. Estudos realizados em planícies fluviais no Brasil. Prec.: precipitação média anual; UF: unidade fitogeográfica (FOM: Floresta Ombrófila Mista; FES: Floresta Estacional Semidecidual; FED: Floresta Estacional Decidual; EGL: Estepe Gramíneo Lenhosa; FOD: Floresta Ombrófila Densa); FV: forma de vida (E: epifítica; G: epifítico, terrestre e/ou rupestre); S: riqueza de bromeliáceas.

Table 5. Studies performed in floodplains in Brazil. Prec.: annual average rainfall; UF: phytogeographic unit (FOM: Mixed Ombrophilous Forest; FES: Seasonal Semideciduous Forest; FED: Seasonal Deciduous Forest; EGL: Grassland; FOD: Dense Ombrophilous Forest), FV: life form (E: epiphytic; G: epiphytic, terrestrial and/or saxicoles); S: bromeliad richness.

\begin{tabular}{lccccc}
\hline Localidade & Autores & $\begin{array}{c}\text { Prec. } \\
(\mathbf{m m})\end{array}$ & UF & FV & S \\
\hline Curitiba - União da Vitória (PR) & Presente estudo & 1.452 & FOM & E & 12 \\
União da Vitória - Foz do Iguaçu (PR) & Presente estudo & 1.798 & FES & E & 6 \\
Araucária - Lapa (PR) & Kersten (2006) & 1.500 & FOM & E & 16 \\
Araucária (PR) & Kersten; Silva (2002) & 1.400 & FOM & E & 9 \\
Curitiba (PR) & Dittrich et al. (1999) & 1.451 & FOM & E & 11 \\
São Mateus (PR) & Silva et al. (1997) & 1.379 & FOM & G & 8 \\
Marcelino Ramos (RS) & Rogalski; Zanin (2003) & 1.400 & FED & E & 10 \\
Eldorado do Sul (RS) & Giongo; Waechter (2004) & 1.310 & EGL & E & 9 \\
Jureia (SP) & Fischer; Araújo (1995) & 4.200 & FOD & E & 15 \\
\hline
\end{tabular}

A análise da similaridade entre os compartimentos resultou em dois grupos que correspondem exatamente às unidades fitogeográficas (Figura 2) que, por sua vez, são uma expressão das características climáticas e altitudinais existentes nas respectivas regiões geográficas. Considerando a FOM, a alta similaridade entre os compartimentos Teresina e Serra Alta (100\%) sugere que a proximidade geográfica e, consequentemente, altitudinal (Tabela 1), entre áreas esteja influenciando na determinação da maior semelhança florística entre os grupos de bromeliáceas epifíticas. Apesar da maior distância geográfica entre as áreas formadoras dos demais subgrupos (Figura 2), pode ainda ser identificada uma distribuição aproximada das áreas de estudo no Segundo Planalto, de montante para jusante do rio, com isolamento da área de estudo localizada no Primeiro Planalto Paranaense (GM Costeiro).

A variável altitude, no entanto, não apresentou relação com a riqueza de bromeliáceas, o que pode estar relacionado com as pequenas diferenças existentes entre as áreas de estudo. Na literatura, são citados os efeitos da altitude em regiões com grandes diferenças altitudinais, como nos Andes, onde o máximo em diversidade ocorre entre 1.000 e 2.000 m s.n.m. (GENTRY; DODSON, 1987). Nos Andes equatorianos, Gilmartin (1973) mostrou que 17 espécies de bromeliáceas ocorrem em menores altitudes, onde as encostas apresentam maior umidade, demonstrando íntima correlação entre o efeito da altitude e da umidade sobre essas epífitas. Na Colômbia, Sudgen (1981) afirma que o fator altitude está relacionado com a interceptação de umidade pelas bromeliáceas, como resultado de maiores períodos de cobertura por nuvens. Hietz; Hietz-Seifert (1995), no México, também discutem a relação de padrões climáticos relacionados a fortes gradientes altitudinais, determinando a riqueza de epífitos nas florestas. Excluindose a variável altitude para explicar as similaridades entre as áreas e a riqueza de bromeliáceas, deve-se 
considerar o grau de intervenção antrópica e a limitação na dispersão das espécies na análise da estrutura das comunidades (YEATON; GLADSTONE, 1982). A distância da fonte de propágulos, como é o caso das epífitas de florestas mais conservadas e/ou de grandes árvores remanescentes na planície, interfere nas taxas de recolonização dos forófitos por espécies anemocóricas, como são a maioria das bromeliáceas (Vriesea e Tillandsia) na FOM (Tabela 2). No entanto, pouco se sabe sobre as distâncias de dispersão dessas espécies (BENZING, 1990), ainda mais em ambientes onde a floresta é naturalmente descontínua, como são as planícies fluviais, e fortemente influenciada pelo canal do rio, onde a luminosidade, umidade e deslocamento do ar são distintos.

Em escala local, a análise de regressão mostrou que a proximidade do rio está positivamente relacionada à riqueza de bromeliáceas (Tabela 4), ou seja, as árvores mais próximas ao rio foram colonizadas por mais espécies. Esse resultado remete à alta umidade relativa do ar originada pela evaporação da água e à maior luminosidade incidente nessa porção das florestas fluviais (ROGALSKI; ZANIN, 2003), proporcionando microambientes favoráveis e singulares para essas plantas, que dependem fortemente de condições microclimáticas para se estabelecer e crescer. Benzing (1990) ressalta que a diversidade de bromeliáceas é maior em posição adjacente ao rio, porque o suprimento contínuo de umidade possibilita a ocorrência, nas árvores das margens, tanto de espécies adaptadas à maior intensidade lumínica como aquelas que necessitam de maior umidade para sobreviver e que, comumente, colonizam forófitos nas porções mais sombreadas da floresta.

Destaca-se também a inclinação das árvores sobre o rio. Apesar da baixa comunalidade da variável inclinação das árvores e sua consequente exclusão da análise de componentes principais, o forte ângulo apresentado pelos indivíduos arbóreos estabelecidos nessa porção adjacente ao rio propicia a formação de substrato mais horizontal, o que também pode ser considerado um fator de favorecimento à colonização das bromeliáceas.

Nas áreas sob domínio da FOM, as menores riquezas concentraram-se no trecho onde o rio Iguaçu apresenta padrão meandrante livre e suas planícies apresentam grandes dimensões - Irati degradação até Teresina degradação (Tabela 2). Esse resultado é ratificado pela relação negativa da riqueza de bromeliáceas com as variáveis largura máxima de planície e largura média do rio (Tabela 4) e leva à suposição de que a menor riqueza de espécies epifíticas nessa região de planícies amplas seja resultante da forte degradação atual do componente arbóreo (CURCIO, 2006), tanto pela proximidade das cidades (São Mateus do Sul e União da Vitória) quanto pela ocupação das planícies por pastagens. Planícies fluviais amplas são mais exploradas para implantação de sistemas produtivos, geralmente com baixa tecnicidade, gerando forte impacto nas florestas remanescentes. Deve-se considerar ainda que, já no início do século passado, a navegação a vapor entre as cidades citadas impôs forte grau de degradação das florestas fluviais nesse trecho do rio Iguaçu, a ponto de arrasar com as florestas formadas, predominantemente, por Sebastiania commersoniana, gerando a necessidade de substituição por Mimosa scabrella Benth. (bracatinga), como especificado na literatura (REISEMBERG, 1973).

Os índices de Shannon e de equabilidade, que são, de modo geral, pouco mais elevados nas superfícies de degradação (Tabela 2), podem ser justificados, em primeira análise, pelo maior tempo de formação em comparação às superfícies de agradação (CURCIO, 2006). Superfícies de agradação estão sendo formadas pela deposição de sedimentos, enquanto que, concomitantemente, verifica-se a retirada de sedimentos na superfície de degradação. Sendo assim, árvores instaladas nas superfícies de degradação estão a mais tempo disponíveis para colonização pelas epífitas. Ademais, superfícies de degradação possuem maior soerguimento das margens (Tabela 1), menor movimentação de relevo e solos predominantemente semi e não-hidromórficos (CURCIO, 2006), o que remete ao resultado da análise de regressão múltipla (Tabela 4), que aponta essas categorias de drenagem dos solos como positivamente relacionadas com a riqueza de bromeliáceas. As superfícies de agradação, por sua vez, possuem sucessivas feições de acúmulo de água, as interbarras com solos hidromórficos, nas quais as árvores, de modo geral, não crescem devido à elevada saturação hídrica, resultando na supressão de substrato para bromeliáceas epifíticas. Desse modo, condicionantes geomorfológicos e pedológicos das superfícies de degradação possibilitam maior densidade de indivíduos arbóreos, desenvolvendo-se por períodos prolongados de tempo, representando mais superfície de fixação para as epífitas. Essa conjunção de fatores sugere que as espécies de bromeliáceas, na planície do rio Iguaçu, respondem à presença e longevidade dos indivíduos arbóreos, os quais, por sua vez, estão intimamente relacionados ao tempo de construção da superfície, assim como às condições pedológicas. Esses resultados indicam também que as 
características geomorfológicas e pedológicas das planícies devem ser inseridas nas discussões relativas à comunidade epifítica, sobretudo de bromeliáceas, uma vez que afetam diretamente a distribuição e o porte dos forófitos, assim como o tempo de existência desses.

Às características geomorfológicas e pedológicas, soma-se a relação positiva da riqueza de bromeliáceas com os diâmetros dos forófitos (DAP) (Tabela 4), que, comumente, são maiores nas porções mais antigas da planície. O diâmetro das árvores pode ser traduzido, de modo geral, pelo tempo em que esses indivíduos estão disponíveis para colonização pelas epífitas, pela área disponível para fixação e pela multiplicidade em nichos. A relação entre as dimensões (altura e diâmetro) dos forófitos e a diversidade dessas epífitas já foi demonstrada em outros estudos (YEATON; GLADSTONE, 1982; HIETZ; HIETZSEIFERT, 1995; FONTOURA et al., 1997; MARTIN et al., 2004; WOLF, 2005; BONNET et al., 2007). Segundo Flores-Palacios; García-Franco (2006), a relação positiva entre a riqueza de espécies epifíticas e o tamanho das árvores está principalmente relacionada com árvores em processo de crescimento e, portanto, com a formação de novos microambientes. Representantes dos maiores indivíduos arbóreos, como Erythrina crista-galli, Vitex megapotamica, Matayba elaeagnoides e Luehea divaricata, eram comumente encontrados isolados na planície, formando locais de sombra para abrigo do gado. Essas árvores apresentavam grande biomassa de epífitas, sobretudo bromeliáceas, o que certamente funcionava como fonte de propágulos para a colonização dos forófitos menores e mais recentes na planície, como Sebastiania commersoniana. Esses dados indicam que a conservação de florestas de grande porte e/ou a manutenção de grandes forófitos em áreas fortemente alteradas são ações fundamentais para a preservação de maior riqueza de bromeliáceas epifíticas na planície do rio Iguaçu.

A diversidade de árvores é apontada como uma variável importante na definição da riqueza de bromeliáceas por Bennett (1986). Na planície do rio Iguaçu, no entanto, essa variável não influenciou nas bromeliáceas (Tabela 4). Esse resultado sugere que, para as áreas estudadas, o maior porte dos indivíduos forofíticos é mais importante do que sua diversificação específica, verificando-se a fixação e o crescimento das bromeliáceas em várias espécies arbóreas, inclusive aquelas bastante comuns, como Sebastiania commersoniana.

\section{CONCLUSÕES}

- Há uma maior riqueza em bromeliáceas nas planícies da Floresta Ombrófila Mista do que na Floresta Estacional Semidecidual, fato atribuído à menor disponibilidade hídrica para as epífitas em direção ao oeste do estado do Paraná, conforme já havia sido identificado para Santa Catarina.

- Superfícies de degradação apresentam mais bromeliáceas epifíticas, o que, provavelmente, está relacionado com a menor saturação hídrica dos solos e com o maior porte dos indivíduos arbóreos, variáveis ambientais positivamente relacionadas com a riqueza de espécies.

- Forófitos que crescem em posição mais próxima ao rio e forófitos de grande porte apresentam maior riqueza de bromeliáceas epifíticas, sendo sua manutenção fator decisivo para a preservação do grupo das bromeliáceas nas áreas estudadas.

\section{AGRADECIMENTOS}

Aos especialistas, pela identificação de bromeliáceas, ao CNPq, pela concessão de auxílio financeiro à primeira autora deste artigo, e aos revisores, pelas sugestões.

\section{REFERENCIAS}

BADER, M.; DUNNÉ J. F.; STUIVER, H. J. Epiphyte distribution in a secondary cloud forest vegetation; a case study of the application of GIS in the epiphyte ecology. Ecotropica, Ulm, v. 6, p. 181195, 2000.

BARDDAL, M. L.; RODERJAN, C. V.; GALVÃO, F.; CURCIO, G. R. Caracterização florística e fitossociológica de um trecho sazonalmente inundável de floresta aluvial, em Araucária, PR. Ciência Florestal, Santa Maria, v. 14, n. 2, p. 37-50, 2004. 
BENNETT, B. C. Patchiness, diversity and abundance relationships of vascular epiphytes. Selbyana, Sarasota, v. 9, p. 70-75, 1986.

BENZING, D. H. Vascular epiphytes. Cambridge: Cambridge University Press, 1990. 354 p.

BOLOS, O.; CERVI, A. C.; HATSCHBACH, G. Estúdios sobre la vegetacion del estado de Paraná (Brasil meridional). Collectanea Botânica, Barcelona, v. 20, p. 79-180, 1991.

BONNET, A. Caracterização fitossociológica das bromeliáceas epifíticas e suas relações com os fatores geomorfológicos e pedológicos da planície do rio Iguaçu, Paraná, Brasil. 289 f. Tese (Doutorado EM Conservação da Natureza) - Setor de Ciências Agrárias, Universidade Federal do Paraná, Curitiba, 2006.

BONNET, A.; QUEIROZ, M. H. Estratificação vertical de bromélias epifíticas em diferentes estádios sucessionais da Floresta Ombrófila Densa, Ilha de Santa Catarina, Santa Catarina, Brasil. Revista Brasileira de Botânica, São Paulo, v. 29, p. 217-228, 2006.

BONNET, A.; QUEIROZ, M. H.; LAVORANTI, O. J. Relações de bromélias epifíticas com características dos forófitos em diferentes estádios sucessionais da Floresta Ombrófila Densa. Floresta, Curitiba, v. 37, p. 83-94, 2007.

BORGO, M.; SILVA, S. M. Epífitos vasculares em fragmentos de Floresta Ombrófila Mista, Curitiba, Paraná, Brasil. Revista Brasileira de Botânica, São Paulo, v. 26, n. 3, p. 391-401, 2003.

BORGO, M.; SILVA, S. M.; PETEAN, M. P. Epífitos vasculares em um remanescente de Floresta Estacional Semidecidual, município de Fênix, PR, Brasil. Acta Biologica Leopoldensia, São Leopoldo, v. 24, p. 121-130, 2002.

BREIER, T. B. O epifitismo vascular em florestas do sudeste do Brasil. 139 f. Tese (Doutorado em Biologia Celular) - Instituo de Biologia, Universidade Estadual de Campinas, Campinas. 2005.

CERVI, A. C.; BORGO, M. Epífitos vasculares no Parque Nacional do Iguaçu, Paraná (Brasil). Levantamento preliminar. Fontqueria, Madrid, v. 55, p. 415-422, 2007.

CURCIO, G. R. Relações entre geologia, geomorfologia, pedologia e fitossociologia nas planícies fluviais do rio Iguaçu, Paraná, Brasil. 488 f. Tese (Doutorado em Conservação da Natureza) - Setor de Ciências Agrárias, Universidade Federal do Paraná, Curitiba, 2006.

DETTKE, G. A.; ORFRINI, A. C.; MILANEZE-GUTIERRE, M. A. Composição florística e distribuição de epífitas vasculares em um remanescente alterado de Floresta Estacional Semidecidual no Paraná, Brasil. Rodriguésia, Rio de Janeiro, v. 59, n. 4, p. 859-872, 2008.

DISLICH, R.; MANTOVANI, W. Flora de epífitas vasculares da Reserva da Cidade Universitária "Armando de Salles Oliveira" (São Paulo, Brasil). Boletim de Botânica da Universidade de São Paulo, São Paulo, v. 17, p. 61-83, 1998.

DITTRICH, V. A. O.; KOZERA, C.; SILVA, S. M. Levantamento florístico dos epífitos vasculares do Parque do Barigui, Curitiba, Paraná, Brasil. Iheringia série botânica, Porto Alegre, v. 52, p. 11-21, 1999.

DRAPER, N. R.; SMITH, H. Applied Regression Analysis. 3. ed. New York: J. Wiley \& Sons, 1995. $709 \mathrm{p}$.

EFRON, B. 1979. Bootstrap methods: another look at Jackknife. Annals of Statistics, Philadelphia, v. 7, p. 1-26, 1981.

EMBRAPA - EMPRESA BRASILEIRA DE PESQUISA AGROPECUÁRIA. Sistema brasileiro de classificação de solos. Rio de Janeiro: Empresa Brasileira de Pesquisa Agropecuária, Centro Nacional de Pesquisa de Solos, 1999. 412 p.

FISCHER, A. E.; ARAÚJO, A. C. Spatial organization of a bromeliad community in the Atlantic rainforest, south-eastern Brazil. Journal of Tropical Ecology, Cambridge, v. 11, p. 559-567, 1995. 
FLORES-PALACIOS, A.; GARCÍA-FRANCO J. G. The relationship between tree size and epiphyte species richness: testing four different hypotheses. Journal of Biogeography, Oxford, v. 33, p. 323-330, 2006.

FONTOURA, T.; SYLVESTRE, L.S.; VAZ, A. M. S.; VIEIRA, C. M. Epífitas vasculares, hemiepífitas e hemiparasitas da Reserva Ecológica de Macaé de Cima. In: LIMA, H. C.; GUEDES-BRUNI, R. R. Serra de Macaé de Cima: diversidade florística e conservação da Mata Atlântica. Rio de Janeiro: Editora do Jardim Botânico do Rio de Janeiro, 1997. p. 89-101.

GAIOTTO, D. F.; ACRA, L. A. Levantamento qualitativo de epífitos da fazenda Gralha Azul, Fazenda Rio Grande, Paraná. Estudos de Biologia, Curitiba, v. 27, n. 60, p. 25-32, 2005.

GENTRY, A. H.; DODSON, C. H. Diversity and Biogeography of Neotropical Vascular Epiphytes. Annals Missouri Botanical Garden, Saint. Louis, v. 74, p. 205-233, 1987.

GILMARTIN, A. J. Transandean distributions of Bromeliaceae in Ecuador. Ecology, New York, v. 54, p. 1389-1393, 1973.

GIONGO, C.; WAECHTER, J. L. Composição florística e estrutura comunitária de epífitos vasculares em uma floresta de galeria na Depressão Central do Rio Grande do Sul. Revista Brasileira de Botânica, São Paulo, v. 27, p. 563-572, 2004.

HIETZ, P. Population dynamics of epiphytes in a Mexican humid montane forest. The Journal of Ecology, Oxford, v. 85, p. 767-775, 1997.

HIETZ, P.; HIETZ-SEIFERT, U. Composition and ecology of vascular epiphyte communities along na altitudinal gradient in central Veracruz, México. Journal of Vegetation Science, Grangärde, v. 6, p. 487498, 1995.

IAPAR - INSTITUTO AGRONÔMICO DO PARANÁ. Cartas climáticas do Estado do Paraná. Londrina, 1994. $45 \mathrm{p}$.

IPNI - INTERNATIONAL PLANT NAME INDEX, THE. The International Plant Names Index. 2008. Disponível em: <http://www.ipni.org>. Acesso em: 20/11/2008.

KAISER, H. F. The varimax criterion for analytic rotation in factor analysis. Psychometrika, Greensboro, v. 23, p. 187-200, 1958.

KERSTEN, R. A. Epifitismo vascular na bacia do alto Iguaçu. 218 f. Tese (Doutorado em Conservação da Natureza) - Setor de Ciências Agrárias, Universidade Federal do Paraná, Curitiba. 2006.

KERSTEN, R. A.; SILVA, S. M. Florística e estrutura do componente epifítico vascular em Floresta ombrófila mista aluvial do rio Barigüi, Paraná, Brasil. Revista Brasileira Botânica, São Paulo, v. 25, p. 259-267, 2002.

MAACK, R. Geografia Física do estado do Paraná. 3. ed. Curitiba: Imprensa Oficial, 2002. 438 p.

MAGURRAN, A. E. Ecological diversity and its measurement. New Jersey: Princeton University Press, 1988. $179 \mathrm{p}$.

MAMEDE, M. C. H.; CORDEIRO, I.; ROSSI, L. Flora vascular da Serra da Juréia, Município de Iguape, São Paulo, Brasil. Boletim do Instituto de Botânica, São Paulo, v. 15, p. 63-124, 2001.

MARTIN, P. H.; SHERMAN, R. E.; FAHEY, T. J. Forty years of tropical forest recovery from agriculture: structure and floristics of secondary and old-growth riparian forests in the Dominican Republic. Biotropica, Washington, DC, v. 36, n. 3, p. 297-317, 2004.

PETEAN, M. P. Florística e estrutura de epífitos vasculares em Floresta Ombrófila Densa Altomontana no Parque Estadual do Pico do Marumbi, Paraná, Brasil. 63 f. Dissertação (Mestrado em Botânica) - Setor de Ciências Biológicas, Universidade Federal do Paraná, Curitiba, 2002. 
PINTO, A. C. R.; DEMATTÊ, M. E. S. P.; PAVANI, M. C. M. D. Composição florística de epífitas (Magnoliophyta) em fragmento de floresta no município de Jaboticabal, SP, Brasil. Científica, São Paulo, v. 23, n. 2, p. 283-289, 1995.

REISEMBERG, A. Conferência: 90 anos da navegação a vapor do rio Iguaçu e Negro. Boletim do Instituto Histórico, Geográfico e Etnográfico Paranaense, Curitiba, v. XVIII, p. 39-65, 1973.

REITZ, R. Bromeliáceas e a malária - bromélia endêmica. Flora Ilustrada Catarinense, Itajaí, fasc. BROM, p. 1-559, 1983.

ROGALSKI, J. M.; ZANIN, E. M. Composição florística de epífitos vasculares no estreito de Augusto César, floresta Estacional Decidual do Rio Uruguai, RS, Brasil. Revista Brasileira de Botânica, São Paulo, v. 26, p. 551-556, 2003.

SCHÜTZ-GATTI, A. L. O componente epifítico vascular na Reserva Natural de Salto Morato, Guaraqueçaba - PR. 93 f. Dissertação (Mestrado em Botânica) - Setor de Ciências Biológicas, Universidade Federal do Paraná, Curitiba, 2000.

SILVA, S. M.; BRITEZ, R. M.; SOUZA, W. S.; MOTTA, J. T. W. Levantamento florístico em área de várzea do rio Iguaçu, São Mateus do Sul, PR, Brasil. Arquivos de Biologia e Tecnologia, Curitiba, v. 40, p. 903-913, 1997.

SIMEPAR, 2005. Dados climáticos. Disponível em: <http://www.simepar.br>. Acesso em: 23/07/2005.

STEEGE, H. TER.; CORNELISSEN, J. H. C. Distribution and Ecology of Vascular Epiphytes in Lowland Rain Forest of Guyana. Biotropica, Washington, DC, v. 21, p. 331-339, 1989.

SUDGEN, A. M. Aspects of the ecology of vascular epiphytes in two Colombian cloud forests. II. Habitat preferences of Bromeliaceae in the Serrania de Macuira. Selbyana, Sarasota, v. 5, p. 264-273, 1981.

VARASSIN, I. G. Estrutura espacial e temporal de uma comunidade de Bromeliaceae e seus polinizadores em floresta Atlântica no sudeste do Brasil. 96 f. Tese (Doutorado em Ecologia) Universidade Estadual de Campinas, Campinas. 2002.

YEATON, R. I.; GLADSTONE, D. E. The pattern of colonization of epiphytes on Calabash Trees (Crescentia alata HBK.) in Guanacaste Province, Costa Rica. Biotropica, Washington, DC, v. 14, p. 137-140, 1982.

WAECHTER, J. L. O epifitismo vascular na planície costeira do Rio Grande do Sul. 163 f. Tese (Doutorado em Ecologia) - Universidade Federal de São Carlos, São Carlos, 1992.

WOLF, J. H. D. The response of epiphytes to anthropogenic disturbance of pine-oak forests in the highlands of Chiapas, Mexico. Forest Ecology and Management, Amsterdam, v. 212, p. 376-393, 2005.

ZOTZ, G.; HIETZ, P. The physiological ecology of vascular epiphytes: current knowledge, open questions. Journal of Experimental Botany, Oxford, v. 52, p. 2067-2078, 2001. 
